\title{
Efecto relativo de la edad en futbol: estudio en un club Vasco profesional Relative age effect in soccer: a study in a professional Basque club
}

\author{
*Bidaurrazaga-Letona I, *Badiola A, ${ }^{*}$ Granados C, ${ }^{* *}$ Lekue JA, ${ }^{* *}$ Amado M, *Gil SM \\ *Universidad del País Vasco. **Athletic de Bilbao
}

\begin{abstract}
Resumen: El efecto relativo de la edad (RAE) ha sido ampliamente estudiado en futbol revelando una distribución de nacimientos sesgada que favorece a los jugadores nacidos en los primeros meses del año. También, se ha observado que el efecto es más relevante en los equipos de alto nivel. Con esto en mente, este estudio analiza el predominio del efecto relativo de la edad en diferentes equipos de un club de futbol profesional así como en los procesos de selección de este. Considerando todo el equipo, la distribución difiere significantemente de la distribución teórica esperada $(p<.05)$. Se encontraron diferencias significativas entre los nacimientos observados y los esperados en las categorías alevines (masculino, $\mathrm{x}^{2}=8.14, p<.05$; femenino, $\mathrm{x}^{2}=11.5$, $p<.01)$. Además, en la categoría femenina no hubo ninguna jugadora nacida entre septiembre y diciembre del año de selección. Sin embargo, no se encontraron diferencias significativas entre los resultados esperados y observados en categorías superiores a pesar de observarse una distribución sesgada. En conjunto, hubo una sobrerrepresentación de jugadores nacidos en los primeros meses del año en todo el equipo confirmando la presencia del RAE en el club. Por otra parte, al analizar el efecto en los procesos de selección confirmamos que este comenzaba antes de que los jugadores ingresasen en el club. Se observaron diferencias significativas en todas las fases de selección entre los jugadores seleccionados y no seleccionados $\left(\mathrm{x}^{2}=18.10-7.80\right.$, $p<.05)$. En consecuencia, podemos decir que el RAE comienza en la identificación temprana de los jugadores.

Palabras clave: Fecha de nacimiento, RAE, fútbol, club profesional.
\end{abstract}

\begin{abstract}
The presence of RAE has been widely reported and studied in soccer revealing skewed birth-date distributions favoring individuals born early in the selection year. Indeed, it has been documented that RAE is more relevant in high level teams. With this in mind, the present study examined the prevalence of the Relative Age Effect (RAE) in different age groups of a professional soccer club and in the selection processes of the same club. Considering the entire club, distribution differs significantly from the theoretical distribution expected $(p<.05)$. Regarding different categories, there were significant differences between the observed and expected births in both alevin categories (male, $\mathrm{x}^{2}=8.14, p<.05$; female, $\mathrm{x}^{2}=11.5, p<.01$ ). Moreover, in womens alevin age group none of the players was born between September and December of the selection year. Nevertheless, they were not significant differences between the expected and observed results in higher categories but a comparatively biased distribution was observed. Overall, we found an over-representation of players born at the beginning of the year confirming the presence of the RAE in the club. When analyzing the effect of RAE in the talent identification process we observed that it begins before the players enter the club. Comparing the distributions of the not-selected players against the selected players significant differences were found in each of the selection phases $\left(\mathrm{x}^{2}=18.10-7.80, p<.05\right)$. Thus, results revealed that the relative age effect acts in the early identification process of the players.
\end{abstract}

Keywords: Birth date, RAE, soccer, professional club.

\section{Introduction}

In order to equalize competition sport, organizations set up systems of age categories based on birthdates of young participants. Thus, children are divided according to their chronological age using specific cut-off dates (Helsen, Van Winckel \& Williams, 2005; Cobley, Baker, Wattie \& MacKenna, 2009). In most European countries the cut-off date used to define categories is the $1^{\text {st }}$ of January. In these countries, the majority of sports teams are made up of participants born between the $1^{\text {st }}$ of January and the $31^{\text {st }}$ of December of the same year. As a result, there can be an age difference of almost one year between the oldest and the youngest participants within any age group (Helsen, Starkes \& Van Winckel, 2005). The intention of these age divisions is to provide developmentally appropriate training and competition, and an equal opportunity to achieve success (Helsen, Starkes \& Van Winckel, 1998). Unfortunately, as children are separated into age groups there are important variations in terms of physical, cognitive, and emotional differences between the youngest and the oldest ones (Musch \& Grondin, 2001).

This difference in chronological age between children in a single age group is known as Relative Age Effect (RAE). The presence of RAE has been widely reported and studied in relation to a large number of cultural contexts and sports such as baseball, ice-hockey, netball, rugby, soccer or tennis revealing skewed birth-date distributions favoring individuals born early in the selection year (Musch \& Grondin, 2001; Barnsley, Thompson \& Barnsley, 1985; Wattie, Cobley \& Baker, 2008; Williams, 2010).

Specifically soccer is characterized by a significant over-

Fecha recepción: 28-07-13- Fecha envío revisores: 28-07-13- Fecha de aceptación: 05-10-13 Iraia Bidaurrazaga Letona

Portal de Lasarte 71,

01007, Vitoria-Gasteiz, Álava (Spain)

iraia84@hotmail.com representation of players born in the early part of the selection year. Accordingly, there is an extensive body of recent literature showing that children born earlier in age-based category are more likely than children born more lately to access higher levels of competition or professional ranks (Musch \& Grondin, 2001). This differentiated access to highlevel training is considered as a kind of discrimination because it disadvantages players born late after the cutoff date reducing their chances to access to the elite level (Musch \& Hay, 1999; Delorme, Boiché \& Raspaud, 2010; Deprez, Vaeyens, Coutts, Lenoir \& Philippaerts, 2012).

The RAE has also been reported in adult soccer players (BaxterJones, 1995; Musch \& Hay, 1999). However, it has been observed that in senior soccer the relative age effect decreased with increasing age. In this line, recent studies have already suggested that players who are born late in the selection year catch up with their older peers at adult age (Mujika, Vaeyens, Matthys, Santisteban, Goiriena \& Philippaerts, 2009). However, Pérez Jiménez and Pain (2008) reported a constant tendency of under-represented players born in the last months of the selection year in a Spanish youth teams, senior clubs and national teams.

Regarding gender, Musch and Grondin (2001) observed stronger RAE in male youth compared with female. This difference could be due to the interaction between biological differences and sociological factors especially during puberty (Baxter-Jones, 1995; Malina, Ribeiro, Aroso \& Cumming, 2007). Indeed, if an early physical development gives an important advantage to young sportsmen in many activities it appears to be a disadvantage for young sportswomen given the existing pressures around their body (Delorme, Boiché \& Raspaud, 2009). In fact, because of the stereotyped representation of the female body, early developed girls may drop out from sport activities reducing potentially RAE (Shakib, 2003; Delorme, Boiché \& Raspaud, 2009). However, there are few studies concerning female samples and the results have been inconsistent. Delorme, Boiché and Raspaud (2009) found no RAE in female basketball and handball players; Vincent and Glamser (2006) found a stronger RAE for males than for females in American soccer 
players and Delorme and Raspaud (2008) observed a more pronounced RAE in female than male in basketball players aged 7-17. Thus, data about women's RAE is scarce and heterogeneous.

This paper presents data from two studies. On one hand, Study 1 investigates the presence of the relative age effect in soccer players of different chronological ages and compares the birth-date distributions between several categories within a professional soccer club to identify whether the relative age effect is influenced by age and gender. On the other hand, Study 2 extends examination of RAE to the selection processes of young players within the club. Collectively, the aim of these studies is to expand our understanding of the RAE in soccer.

\section{Study 1}

RAE has been extensively studied but its underlying causes remain unknown. Therefore, investigations are still needed. The purpose of this study was to compare the birth-date distributions between several subgroups in a professional soccer club and to identify whether the relative age effect is inûuenced by age and gender.

\section{Methodology}

\section{Participants}

Table 1 presents the sample of the 197 soccer players of a professional club that participated in this study. The senior male group included 28 professional soccer players who played for the senior team of the Athletic Club of Bilbao in the Spanish Primera División. The senior female group included 23 non-professional soccer players who played in the women's team of the Athletic Club of Bilbao in the Spanish women's Primera División. The remaining groups were represented by 146 female and male players who attended the Athletic Club Bilbao youth development program (divided in three age groups: juvenil, infantil and alevin).

\begin{tabular}{ccccc}
\multicolumn{5}{c}{ Table 1. Numb er of players for each of the age groups in the club (Study 1). } \\
\hline Age Group & Gender & Sample & Level & Birth-year \\
\hline \multirow{2}{*}{ Senior } & Male & 28 & $1^{\mathrm{a}}$ División & $1980-1995$ \\
& Female & 23 & $1^{\mathrm{a}}$ División & $1976-1995$ \\
& Male & 23 & División de Honor Juvenil & $1992-1995$ \\
Juvenil & Female & 19 & $2^{\mathrm{a}}$ División Femenina & $1992-1997$ \\
& Male & 32 & Deporte Escol ar/ Liga E Infantil & $1999-2000$ \\
Infantil & Female & 23 & Deporte Escolar/ Liga Infantil & $1999-2000$ \\
& Male & 31 & Deporte Escolar/ Liga A Alevin & 2001 \\
Alevin & Female & 18 & Deporte Es colar/Alevin Liga B & 2001 \\
\hline
\end{tabular}

\section{Protocol}

For encoding data, the selection year corresponded with the regular calendar year that started January $1^{\text {st }}$ and ended December $31^{\text {st }}$ of the same year. The date of birth of the participants was divided in four quarters: quarter $1=1^{\text {st }}$ January to $31^{\text {st }}$ March; quarter $2=1^{\text {st }}$ April to $30^{\text {th }}$ June; quarter $3=1^{\text {st }}$ July to $30^{\text {th }}$ September; quarter $4=1^{\text {st }}$ October

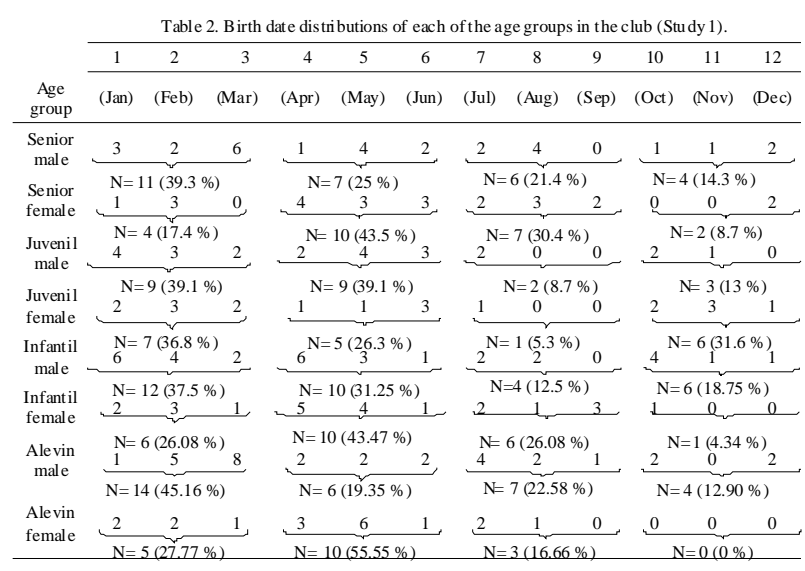

to $31^{\text {st }}$ December. The month and birth quarter were considered for all soccer players. The expected birth-date distributions were recorded from the representative birth-dates of population of the Basque Country.

The sample was compiled using different sources. The data pertaining to the senior (male and female) and juvenil (male and female) teams was obtained from the website of the Athletic Club of Bilbao. Data from infantil and alevin categories (both male and female) was provided by the club. The data included the player's dates of birth (day, month and year) and age group. It is worth mentioning that until 2012 the club did not recruit young girls so this was the first year in the club for the women's alevin and infantil categories. Data relating to the Basque population was obtained from the Spanish National Institute of Statistics.

\section{Statistics}

A chi-square goodness-of-fit test was used to assess the differences between the observed and expected birth date distributions. The level of significance was set at $p<.05$. Expected birth date distribution was based on the distribution of live births of the Basque Country. The reason for this comparison was that Athletic Club of Bilbao is characterized by its particular selection policy, requiring all players to be either born or developed in the Basque Country (Mujika, et al., 2009).

\section{Results}

The birth dates of all participants are shown in Table 1. Of all participants, $68.53 \%$ had been born in the first semester. Furthermore, there was a predominance of players born in the first quarter of the year (34.52\%). As shown in Figure 1, this observed distribution differs significantly from the theoretical distribution expected $(p<.05)$.

Regarding birth distribution in each age group, the percentage of players born in the first quarter of the selection year was $39.3 \%$ in senior male, $17.4 \%$ in senior female, $29.1 \%$ in juvenil male, $36.8 \%$ in juvenil female, 37.5\% in infantil male, 26.08\% in infantil female, 45.16\% in alevin male and $27.77 \%$ in alevin female. Players born in the last fourth quarter represented $14.3 \%, 8.7 \%, 13 \%, 31.6 \%, 18.75 \%, 4.34 \%$, $12.90 \%$ and $0 \%$, respectively.

There were significant differences between the observed and expected births in both alevin categories (male, $x^{2}=8.14, p<.05$; female, $x^{2}=$ 11.5, $p<.01$ ) (See Table 3). Nevertheless, they were not statistically significant differences between the expected and observed results in higher categories but a comparatively biased distribution was observed. Thus, early-born players were clearly favored only in some cases, but in every case late-born players were disadvantaged. It is worth noting that there was a dramatic effect in the female alevin age group with none of the players being born between September and December of the selection year.

\section{Discussion}

In the present study we examined the prevalence of the Relative Age Effect (RAE) in different age groups of a professional soccer club. We found an over-representation of players born at the beginning of the year in all the categories confirming the presence of the RAE in the club. In fact, almost $69 \%$ of the players were born in the first semester. Indeed, it has been well documented that the presence of the RAE is more relevant in high level teams. Moreover, Pérez Jiménez and Pain (2008) observed that club regarded as successful from big cities and with important reputations for their youth teams are the ones strongly characterized by RAE.

Regarding each age group, the study revealed a biased distribution with an under representation of players born in the last quarter of the year in all cases. This skewed birth distribution was statistically significant in alevin categories in agreement with previous studies. Delorme and Raspaud (2009) observed RAE as soon as the age of 7 among basketball players (girls and boys) and other studies have shown 


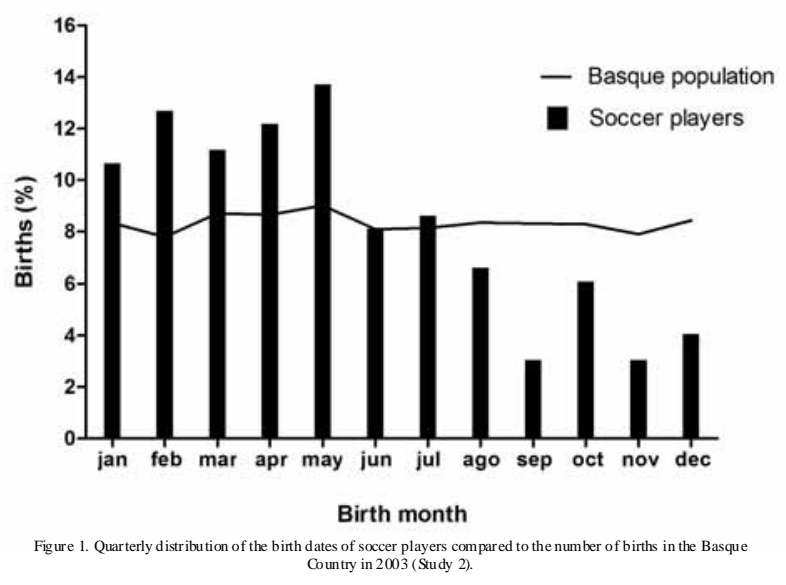

similar conclusions (Baxter-Jones, 1995; Helsen, Van Winckel \& Williams, 2005; Gil, Ruiz, Irazusta, Gil \& Irazusta, 2007). However, our results contrast with some studies that have confirmed this effect in players aged 13-14 and older, but have shown inconsistent results for younger players (Helsen, Starkes \& Van Winckel, 1998).

RAE did not increase in higher categories. A clearly unequal distribution was observed when compared with the Basque population but the effect was less pronounced than that of the young teams. In fact, recent studies have already suggested that players who are born late in the selection year catch up with their older peers at adult age when they may lose their possible maturation advantage (Mujika, et al., 2009; Baxter-Jones, 1995; Malina, Bouchard \& Bar-Or, 2004; Vaeyens, Philippaerts \& Malina, 2005). Besides, once their physical development is completed, and the advantages for early-born players are eliminated, players that were left out in the early selection processes may have a later chance to make it to the elite level (Pérez Jiménez \& Pain, 2008).

The impact of gender in RAE has shown heterogeneous results because of the paucity of data and few studies have been conducted with female players. Nevertheless, most of the studies undertaken in team sports suggest that there is no RAE or that there is a weak trend among adult females while the effect is more significant in young girls. However, this data contrasts with our results. In our study we observed a skewed birth distribution by quarter for all female age groups, including adults. Even if the pattern is not as significant as in youth categories, there was a clear under-representation of players born late in the year. These results are in agreement with Delorme and Raspaud (2008) who observed an under-representation of late borns in French female soccer players in all age groups with more significant skewed distribution in young girls. In line with this, we observed a dramatic effect in female alevin players with none of the players being born in the last quarter of the year. We believe that this result may be a consequence of the talent identification procedures were the coaches tend to select those players who are physically stronger. In line with this, Delorme and Raspaud (2010) observed that young girls born early in the selection year begin to play soccer before their younger peers. Thus, those born in the last quarter show a kind of «self-selection» process even before trying the activity. Therefore, they concluded that RAE could be a result of these two simultaneous phenomenons.

\section{Study 2}

Study 2 builds upon the results of Study 1 while attempting to overcome why RAE is more pronounced in younger categories in this professional club. Thus, the objective of the present study was to analyse the effect of RAE in the process of talent identification to observe if RAE begins before the players enter the club. This club has a particular philosophy of employing only locally (Basque Country) born players or developed from childhood within the club. Therefore, identifying players with the potential to become high level professionals is a major issue for this club. For this reason, each season, technical staff of the Athletic Club de Bilbao select soccer players from different clubs of the county to enter the youngest team in this club (alevin category).

Thereby, the selection process goes through three phases. First phase: during the first months of the season a number of players are selected from all the soccer players around the county. Second phase: between this first selection and the end of the season some of those preselected players continue training in their original clubs, but attend one training session per week within the club's facilities under the supervision of the club's coaches. Third phase: at the end of the season technical staff makes a small selection of players to definitely join the club the next season.

\begin{tabular}{|c|c|c|c|c|c|}
\hline & $\mathrm{N}$ & First & Second & Third & Fourth \\
\hline Basque population & 12790 & 4570 (23.71\%) & $5036(26.13 \%)$ & 4865 (25.24\%) & 4799 (24.90\%) \\
\hline $\begin{array}{c}\text { County soccer } \\
\text { players }\end{array}$ & 567 & $162(28.57 \%)$ & $141(24.86 \%)$ & $132(23.28 \%)$ & $132(23.28 \%)$ \\
\hline $\begin{array}{l}\text { Selected players } \\
\text { (phas 1) }\end{array}$ & 112 & 40 (35.71\%) & 33 (29.46\%) & 22 (19.64\%) & 17 (15.17\%) \\
\hline $\begin{array}{l}\text { Selected players } \\
\text { (phas 2) }\end{array}$ & 37 & 14 (37.83\%) & 7 (18.91\%) & 10 (27.02\%) & $6(16.21 \%)$ \\
\hline $\begin{array}{c}\text { Selected players } \\
\text { (phas 3) }\end{array}$ & 16 & $5(31.25 \%)$ & $5(31.25 \%)$ & $3(18.75 \%)$ & $3(18.75 \%)$ \\
\hline
\end{tabular}

\section{Methodology}

\section{Participants}

Table 3 presents the sample of the 567 young male soccer players of different clubs of the county (born in 2003) that participated in this study as well as the Basque population born in the same year. 112 players were in the pre-selection group (phase 1); 37 players were selected to attend one training session per week with the club (phase 2) and 16 players were chosen to join the youngest team of the club the next season (phase 3 ).

\section{Protocol}

The protocol was the same used in Study 1 . The selection year corresponded with the regular calendar year. The date of birth of the participants was divided in four quarters; the month and birth quarter were considered for all soccer players. The expected birth-date distributions were recorded from the representative birth-dates of population of the Basque Country born in 2003. All the data was provided by the club. Data relating to the Basque population was obtained from the Spanish National Institute of Statistics.

\section{Statistics}

A chi-square goodness-of-fit test was used to assess the differences between the observed and expected birth date distributions. The level of significance was set at $p<0.05$. Expected birth date distribution was based on the distribution of live births of the Basque Country in 2003.

\begin{tabular}{lccccccc}
\multicolumn{7}{c}{ Table 4. Birth date distribut ions of the different phases of the selection process (Study 2). } \\
\hline & First & Second & Third & Fourth & Total & $x^{2}$ & $p$ \\
\hline Countys occer players & & & & & & .61 & .894 \\
Number & 162 & 141 & 132 & 132 & 567 & & \\
$\%$ & 28.57 & 24.86 & 23.28 & 23.28 & & & \\
Expected & 134 & 148 & 143 & 142 & & & \\
Selected players (phase 1) & & & & & & 5.68 & .128 \\
Number & 40 & 33 & 22 & 17 & 112 & & \\
$\%$ & 35.71 & 29.46 & 19.64 & 15.17 & & & \\
Expected & 27 & 29 & 28 & 28 & & & \\
Selected players (phase 2) & & & & & & 6.29 & .098 \\
Number & 14 & 7 & 10 & 6 & 37 & & \\
$\%$ & 37.83 & 18.91 & 27.02 & 16.21 & & & \\
Expected & 9 & 9 & 10 & 9 & & & \\
Selected players (phase 3) & & & & & & 3.31 & 345 \\
Number & 5 & 5 & 3 & 3 & 16 & & \\
$\%$ & 31.25 & 31.25 & 18.75 & 18.75 & & & \\
Expected & 4 & 4 & 4 & 4 & & & \\
Basque population & & & & & & & \\
Number & 4570 & 5036 & 4865 & 4799 & 19270 & & \\
$\%$ & 23.71 & 26.13 & 25.24 & 24.90 & & & \\
\hline
\end{tabular}




\section{Results}

The birth dates of all participants are shown in Table 3. Of all participants, $53.43 \%$ had been born in the first semester and $46.56 \%$ in the second. These results are slightly skewed but similar to those seen in the general population (49.84\% and $50.15 \%$ for the first and second semester, respectively). Furthermore, if we divide the year in four quarters we can observe that the distribution is similar in both Basque population (Q1: 23.71\%, Q2: 26.13\%, Q3: 25.24\%, Q4: 24.90\%) and the overall number of players who played in the county (Q1: $28.57 \%$, Q2: 24.86\%, Q3: 23.28\%, Q4: 23.28\%).

Regarding birth distribution in the selection process, the percentage of selected players born in the first quarter of the selection year was $35.71 \%$ in phase $1,37.83 \%$ in phase 2 , and $31.25 \%$ in phase 3 . Players born in the last fourth quarter represented $15.17 \%, 16.21 \%$ and $18.75 \%$, respectively. Even if a comparatively biased distribution was observed there were not statistically significant differences in the observed and expected births in any of the selection phases (Table 4). However, we observed significant differences in the birth distributions of the selected players against the non-selected: in phase $1\left(x^{2}=9.75, p<.05\right)$, phase 2 $\left(x^{2}=7.80, p<.05\right)$, and phase $3\left(x^{2}=18.10, p<.01\right)$ (See Figure 2$)$

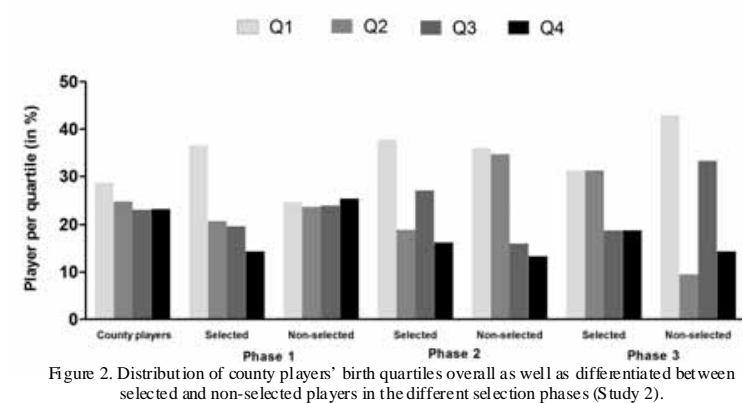

\section{Discussion}

The aim of the Study 2 was to analyse the effect of RAE in the process of talent identification to observe if RAE begins before the players enter the club. Previous findings have shown that the existence of RAE is not so obvious in lower soccer skill levels (Cobley, et al., 2009; Wattie, et al., 2012). In elite youth groups the number of players born in the ûrst quarter was up to more than $20 \%$ above the expected number of births registered in the general population while in the regional and school clubs the effect was low-to-moderate (Mujika, et al., 2009). This data is in line with the results we have obtained. Even if a there was a comparatively biased distribution in the birth distribution, there were not statistically significant differences in the observed and expected births when comparing the Basque population, youth soccer players who played in the county and those who were selected in each of the phases.

Regarding selection process, recent literature shows that children born earlier in age-based category are more likely to access higher levels of competition and to be recognized like talented (Musch \& Grondin, 2001). Moreover, these players are transferred to next categories and consequently receive higher quality coaching (Pérez Jiménez \& Pain, 2008). Some studies conclude that the relatively older players are recognized like talented due to their physical superiority and are selected purely because of maturity-related advantages (Mujika, et al., 2009). Thus, selection procedures that are based in anthropometric and performance control variables may eliminate late maturers with potential (Gil, Badiola, Bidaurrazaga-Letona, Zabala-Lili, Gravina, SantosConcejero, et al., 2013). This differentiated access to high-level training is considered as a kind of discrimination because it disadvantages players born late after the cutoff date reducing their chances to access to the elite (Musch \& Hay, 1999; Delorme, Boiché \& Raspaud, 2010; Deprez, et al., 2012).
In line with this, we observed a biased distribution in births in selected players when compared to non-selected players in all selection phases. In fact, this difference was more pronounced in the first phase and continued during all the selection. In line with this, results from previous works have already observed that age is a determinant factor in the selection process. In a study conducted to assess if anthropometric variables, maturity related variables and performance of physical tests were different amongst players of different relative age born in the same year, older players displayed better results in the velocity, the agility, the jump tests and the Yo-Yo IT level 1. Thereby, the authors concluded that age is a determinant factor in the selection process, probably due to the fact that older boys demonstrate better performance in various physical tests than theiryounger peers (Gil, etal., 2013).Alike, Figueiredo et al. (2011) revealed that age and adiposity were primary predictors of functional capacity in soccer players aged 11-12 years. Indeed, we believe that the most decisive point of the process of training elite players may be the moment of their recruiting. This is in agreement with Gutierrez et al., (2010) that also observed that the main cause of RAE in elite soccer would seem to be early talent identification.

\section{Conclusions}

Taking together, it is evident in the present study that there was an over-representation of players born at the beginning of the year in all the age groups confirming the presence of the RAE in the club. The study revealed an under-representation of players born in the last quarter of the year in all age groups but especially in the younger (alevin) categories. In the rest of the categories, the bias towards the over-representation of early borns in the selection year was less pronounced but the players born at the very end of the year were still under-represented. It is worth noting that there was a skewed birth distribution by quarter for all female age categories, including adults and that there were not alevin female players born in the last quarter of the selection year.

Regarding the effect of RAE in the talent identification process, we observed that RAE begins before the players enter the club. In fact, results revealed that the relative age effect acts in the early identification process of the players demonstrating that earliest levels of talent identification and selection need to be modified to provide a more equal selection process.

Despite all that has been learned about RAE, the reasons for this unequal distribution has been widely hypothesized but not clearly demonstrated. Considering all these, more research to explore the problem and identify the roots of RAE in detail is needed.

\section{References}

Barnsley, R., Thompson, A.H, \& Barnsley, P.E. (1985). Hockey success and birth-date: The relative age effect. Journal of the Canadian Association of Health, Physical Education and Recreation, 51, 2328.

Baxter-Jones, A. (1995). Growth and development of young athletes. Should competition levels be age related? Sports Medicine, 20, 5964.

Cobley, S., Baker, J., Wattie, N., \& McKenna, J. (2009). Annual agegrouping and athlete development: A meta-analytical review of relative age effects in sport. Sports Medicine, 39, 235-256.

Delorme, N., Boiché, J., \& Raspaud, M. (2009). The Relative Age Effect in Elite Sport: The French Case. Research Quarterly for Exercise and Sport, 80(2), 336-344.

Delorme, N., Boiché, J., \& Raspaud, M. (2010). Relative age effect in elite sports: Methodological bias or real discrimination? European Journal of Sport Science, 10, 91-96.

Delorme, N., \& Raspaud, M. (2008). The relative age effect in young French basketball players: A study on the whole population. Scandinavian Journal of Medicine \& Science in Sports, 19(2), 235242. 
Deprez, D., Vaeyens, R., Coutts, A. J., Lenoir, M., \& Philippaerts, R. (2012) Relative age effect and Yo-Yo IR1 in youth soccer. International Journal of Sports Medicine, 33, 987-993

Gil, S., Ruiz, F., Irazusta, A., Gil, J., \& Irazusta, J. (2007). Selection of young soccer players in terms of anthropometric and physiological factors. The Journal of Sports Medicine and Physical Fitness, 47, 25-32.

Gil, S.M., Badiola, A., Bidaurrazaga-Letona, I., Zabala-Lili, J., Gravina, L., Santos-Concejero, J., Lekue, J., \& Granados, C. (2013). Relationship between the Relative Age Effect and anthropometry, maturity and performance in young soccer players. Journal of Sports Sciences. doi: 10.1080/02640414.2013.832355.

Gutierrez, D., Pastor, J.C., Gonzalez, S., \& Contreras, J. (2010). The relative age effect in youth soccer players from Spain. Journal of Science and Medicine, 9, 190-198.

Helsen, W.F., Starkes, J.L., \& Van Winckel, J. (1998). The influence of relative age on success and drop out in male soccer players. American Journal of Human Biology, 10, 791-798.

Helsen, W.F., Van Winckel, J., \& Williams, A.M. (2005). The relative age effect in youth soccer across Europe. Journal of Sports Sciences, 23, 629-636.

Malina, R.M., Ribeiro, B., Aroso, J., \& Cumming, S.P. (2007). Characteristics of youth soccer players aged 13-15 years classified by skill level. British Journal of Sports Medicine, 41, 290-295.

Malina, R., Bouchard, C., \& Bar-Or, O. (2004). Growth, maturation, and physical activity (2nd ed.) Human Kinetics.

Mujika, I., Vaeyens, R., Matthys, S.P., Santisteban, J., Goiriena, J., \&
Philippaerts, R. (2009). The relative age effect in a professional football club setting. Journal of Sports Sciences, 27, 1153-1158.

Musch, J., \& Grondin, S. (2001). Unequal competition as an impediment to personal development: A review of the relative age effect in sport. Developmental Review, 21, 147-167.

Musch, J., \& Hay, R. (1999). The relative age effect in soccer: crosscultural evidence for a systematic discrimination against children born late in the competition year. Sociology of Sport Journal, 16, 54-64

Pérez Jiménez, I., \& Pain, M.T.G (2008). Relative age effect in Spanish association football: Its extent and implications for wasted potential. Journal of Sports Sciences, 26, 995-1003.

Shakib, S. (2003). Female Basketball Participation. Negotiating the Conflation of Peer Status from Childhood Throught Puberty. American Behavioral Scientist, 46, 1405-1422.

Vaeyens, R., Philippaerts, R. M., \& Malina, R. M. (2005). The relative age effect in soccer: Amatch-related perspective. Journal of Sports Sciences, 23, 747-756.

Vincent, J., \& Glamser, F.D. (2006). Gender differences in the relative age effect among US Olympic Development Program youth soccer players. Journal of Sports Science, 24, 405-414.

Wattie, N., Cobley, S., \& Baker, J. (2008). Towards a unified understanding of relative age effects. Journal of Sports Sciences, 26(13), 1403-1409.

Williams, J.H. (2010). Relative age effect in youth soccer: Analysis of the FIFA U17 world cup competition. Scandinavian Journal of Medicine \& Science in Sports, 20(3), 502-508.

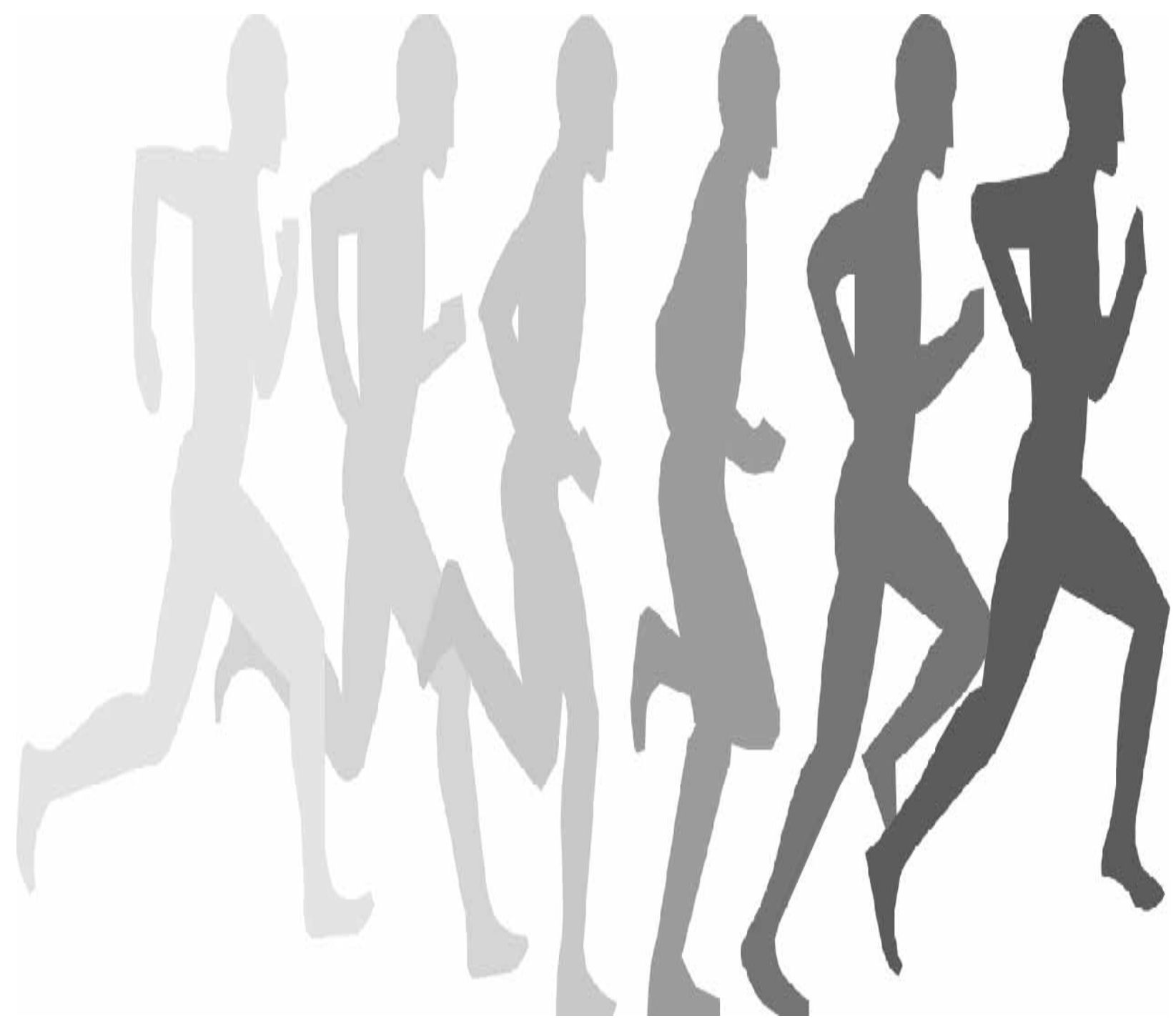

